\title{
Assessment of diastolic function from velocity- encoded cardiac magnetic resonance data in patients with hypertrophic cardiomyopathy
}

Golmehr Ashrafpoor ${ }^{1 *}$, Nadjia Kachenoura², Emilie Bollache ${ }^{2}$, Laurent Macron ${ }^{1}$, Arshid Azarine ${ }^{1}$, Eric Bruguière ${ }^{1}$ Sébastien Fontaine ${ }^{1}$, Michel Desnos ${ }^{1}$, Albert A Hagège ${ }^{1}$, Elie Mousseaux ${ }^{1,2}$, Alban Redheuil $^{1,2}$

From 16th Annual SCMR Scientific Sessions

San Francisco, CA, USA. 31 January - 3 February 2013

\section{Background}

Diastolic dysfunction evaluation may be relevant for early diagnosis of hypertrophic cardiomyopathy (HCM) and subsequent risk assessment. The aim of our study was to assess phase contrast cardiac magnetic resonance (PCCMR) diastolic parameters obtained with a semi-automated method in relation to left ventricular (LV) remodeling and late gadolinium enhancement (LGE) in patients with HCM.

\section{Methods}

We studied 48 patients with HCM and 23 healthy volunteers matched for age, sex and body surface area (BSA). Mitral inflow and myocardial velocities were assessed using through plane 2D PC-CMR $(\mathrm{VENC}=150 \mathrm{~cm} / \mathrm{s}$ and $20 \mathrm{~cm} / \mathrm{s}$ respectively). Transmitral peak flow-rates (Ef and Af) and early E' peak myocardial longitudinal velocity were obtained semi-automatically using CardFlow (INSERM U678). LV volumes, segmental thickness and mass were obtained from SSFP images. LGE volume was quantified semi-automatically using a 6 SD threshold.

\section{Results}

Peak myocardial longitudinal velocity E' was significantly lower and E/E' was significantly higher in patients with HCM compared with controls (Table). We found a linear relationship between decreased E' and increased LV mass index $(\mathrm{p}<0.0001)$, decreased mass/end-diastolic volume $(\mathrm{M} / \mathrm{EDV})$ ratio $(\mathrm{p}<0.0001)$, increased LGE mass $(\mathrm{p}=0.04)$ and LGE extension $(\mathrm{p}=0.04)$. The relationships between $\mathrm{E}^{\prime}$ and LV mass index and M/EDV were independent of age, gender, BSA and systolic blood pressure $(\mathrm{p}<0.001)$.

\section{Conclusions}

Comparison of patients with HCM and healthy volunteers by CMR showed significantly altered LV diastolic function related to LV hypertrophy and LGE. Assessment of diastolic function may be considered for a comprehensive cardiac evaluation in HCM.

\section{Funding}

None.

Table 1

\begin{tabular}{cccc}
\hline & Controls (n=23) & HCM $(\mathrm{n}=48)$ & $\mathrm{p}$ \\
\hline LV mass (g) & $132(33)$ & $195(69)$ & 0.0001 \\
LV mass index (g/m2) & $69(13)$ & $106(36)$ & $<0.0001$ \\
EDV $(\mathrm{ml})$ & $139(37)$ & $151(45)$ & $\mathrm{NS}$ \\
ESV $(\mathrm{ml})$ & $50(14)$ & $51(23)$ & $\mathrm{NS}$ \\
Mass/EDV $(\mathrm{g} / \mathrm{ml})$ & $0.99(0.3)$ & $1.35(0.5)$ & 0.0026 \\
LV ejection fraction (\%) & $64(5)$ & $66(10)$ & $\mathrm{NS}$ \\
Maximal wall thickness (mm) & $\mathrm{NA}$ & $20(4)$ & $\mathrm{NA}$ \\
Extent of LV hypertrophy (\%) & $\mathrm{NA}$ & $16(17)$ & $\mathrm{NA}$ \\
LGE (g) & $\mathrm{NA}$ & $4.1(4.6)$ & $\mathrm{NA}$ \\
LGE (\%) & $\mathrm{NA}$ & $2.3(2.2)$ & $\mathrm{NA}$ \\
Ef/Af & $1.21(0.7)$ & $1.47(2.3)$ & $\mathrm{NS}$ \\
E' (cm/s) & $8.6(4.7)$ & $3.4(1.6)$ & $<0.0001$ \\
E/E' & $8.1(4.3)$ & $25.3(18.6)$ & 0.0001 \\
DT (ms) & $213.9(72.1)$ & $241.4(67.4)$ & 0.11 \\
\hline
\end{tabular}

LV, left ventricular; EDV, end-diastolic volume; ESV, end-systolic volume; LGE, late gadolinium enhancement; DT, deceleration time

${ }^{1}$ Hôpital Européen Georges Pompidou, Paris, France

Full list of author information is available at the end of the article

(c) 2013 Ashrafpoor et al; licensee BioMed Central Ltd. This is an Open Access article distributed under the terms of the Creative 


\section{Author details}

${ }^{1}$ Hôpital Européen Georges Pompidou, Paris, France. ${ }^{2}$ Inserm U678,

Université Pierre et Marie Curie Paris 6, Paris, France.

Published: 30 January 2013

\section{doi:10.1186/1532-429X-15-S1-P170}

Cite this article as: Ashrafpoor et al:: Assessment of diastolic function from velocity-encoded cardiac magnetic resonance data in patients with hypertrophic cardiomyopathy. Journal of Cardiovascular Magnetic Resonance 2013 15(Suppl 1):P170.

Submit your next manuscript to BioMed Central and take full advantage of:

- Convenient online submission

- Thorough peer review

- No space constraints or color figure charges

- Immediate publication on acceptance

- Inclusion in PubMed, CAS, Scopus and Google Scholar

- Research which is freely available for redistribution

Submit your manuscript at www.biomedcentral.com/submit
Ciomed Central 